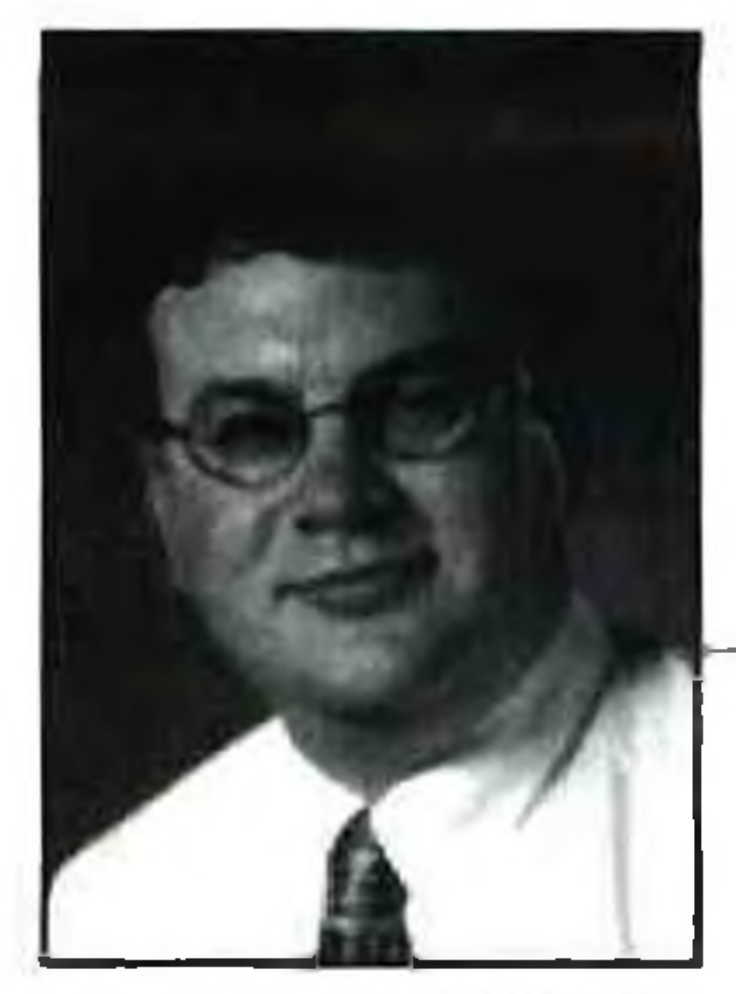

Michael C. Sturman

\title{
Award for the Best Cornell Quarterly Article in 2002
}

\section{From the Editor}

I am pleased to announce that the following arricle has been named Cornell Quarterly article of the year for 2002 (it appeared in the August 2002 issue):

\section{"Assessing the Profitability of Premium Players,"} by Anthony Lucas, Jim Kilby, and Jocelina Santos

The Center for Hospitality Research sponsored this second annual award for the best Cornell Quarterly article ( $C Q$ classics, book reviews, and commentaries are ineligible). Because 1 took over as editor on July 1, 2002, both previous editor Michacl Lynn and I jointly nominated six arricles. Editorial-board members were then asked to vote for their three top choices. Because there was a tie for third place, four papers became finalists. As the last step, members of CHR's industry advisory board picked the winner from among the finalists.

\section{Criteria for Selection}

Arricles were judged on how well they meer the mission of Cornell Hotel and Restaurant Administration Quarterly, which is to provide research-based insights for the practice of hospitality. More specifically, its purpose is to present managers and exccutives in the industry with theories, research findings, and other information that will change the way they define, consider, and solve business problems. Thus, articles were judged on both relevance and rigor.

\section{This Year's Nominees}

All nominees deserve accolades for a job well done. In addition to the arricle by Lucas, Kilby, and Santos, the 2002 nominees were:

- Christopher Knable, "Recovering Hospitalicy at Ground Zero" (October);

- Steven C. Michael, "Undermarketed! Why the Hospitaliry Industry Shorts Irself on Advertising" (April);

- Gail Ayala Taylor and Sylvia Long-Tolhert, "Coupon Promotions in Quick-service Restaurants: Preaching to the Converted?" (August):

- J. Bruce Tracey and Arthur Nathan, "The Strategic and Operational Roles of Human Resources: An Emerging Model (August); and

- Kare Walsh, "Service-delivery Strategies: Three Approaches to Consulting for Hospicality" (December).

\section{Finalists and Winner}

Each member of CQ's editorial board read the nominated articles and rank ordered the best three. Three points were assigned for each first-place ranking, two points were assigned for each second-place ranking, and one point was assigned for each third-place ranking. The scores were extremely close, and (as mentioned) there was a tie for third. The four articles with the highest point totals (in alphabetical order) were those written by (1) Knable, (2) Lucus, Kilby, and Santos, (3) Tracey and Nathan, and (4) Walsh.

The four finalists were then rank ordered by members of the CHR's advisory board, using the same point scheme.

Congratulations to the winning authors and to the other finalists and nominees! Thanks to all the authors who contributed articles to Cornell Quarterly in 2002.-M.C.S. 